\title{
Cardiovascular Lesion Indicator
}

National Cancer Institute

\section{Source}

National Cancer Institute. Cardiovascular Lesion Indicator. NCI Thesaurus. Code C161485.

An indication as to whether a cardiovascular lesion is present. 